\title{
Seroprevalence study of infection with influenza A(H1N1)pdm09 virus in San Felipe Town, Chile
}

\author{
Olea Andrea ${ }^{1}$, Fasce Rodrigo ${ }^{2}$, Aguilera Ximena ${ }^{3}$, Oliva Otavio ${ }^{4}$, Muñoz Sergio ${ }^{4}$, García Maritza $^{1}$, \\ Pedroni Elena $^{4}$, Nájera Manuel $^{3}$, Guerrero Andrea ${ }^{1}$, Bustos Patricia ${ }^{2}$, Mora Judith ${ }^{2}$, Vega Jeanette ${ }^{3}$, \\ Cerda Jaime ${ }^{5}$, Abarca Katia ${ }^{5}$, McCarron $\mathrm{Meg}^{6}$, Widdowson Marc-Alain ${ }^{6}$, Castillo Ernesto ${ }^{7}$, \\ Alvarado Sergio ${ }^{7}$, Quijada Sandra ${ }^{7}$, Gallegos Doris $^{1}$, González Claudia ${ }^{8}$ \\ ${ }^{1}$ Center of Epidemiology and Health Policies Department, Faculty of Medicine, Universidad del Desarrollo, Concepción, Chile \\ ${ }^{2}$ Section of Respiratory and Exanthematous viruses, Sub-Department of Clinical Virology, Institute of Public Health, Ministry of \\ Health, Santiago, Chile \\ ${ }^{3}$ Center of Epidemiology and Health Policies of the Universidad del Desarrollo, Concepción, Chile \\ ${ }^{4}$ Panamerican Health Organization, Washington DC, USA \\ ${ }^{5}$ Public Health Department and Pediatrics Division, Faculty of Medicine, Pontifical Catholic University of Chile, Santiago, Chile \\ ${ }^{6}$ Centers for Diseases Control and Prevention, Atlanta, USA \\ ${ }^{7}$ Center for Micro Data, Economics Department, University of Chile, Santiago, Chile \\ ${ }^{8}$ Epidemiology and Health Policies Department, Universidad del Desarrollo, Concepción, Chile \\ Email: norman din@hotmail.com
}

Received 14 August 2013; revised 16 September 2013; accepted 1 October 2013

Copyright (C) 2013 Olea Andrea et al. This is an open access article distributed under the Creative Commons Attribution License, which permits unrestricted use, distribution, and reproduction in any medium, provided the original work is properly cited.

\section{ABSTRACT}

Objective: To know the natural history of the first wave of pandemic influenza $A(\mathrm{H} 1 \mathrm{~N} 1)$ pdm09 in the Southern hemisphere, through the detection of antibodies against influenza $\mathrm{A}(\mathrm{H} 1 \mathrm{N1}) \mathrm{pdm09}$ in a selected community, to estimate the population attack rate and its variations, the consultation rates, hospitallization and mortality rates. Methodology: A representative random sample of the population of a commune in Chile (San Felipe) was interviewed and taken blood samples between January and March 2010. A study against the antibodies of the influenza A(H1N1) pdm09 virus was conducted, by the technique of the Hemaglutination Inhibition (HAI) according to standardized methodology. Subjects with antibody titers $\geq 1: 40$ were considered positive. Results: $13.5 \%$ of the population of San Felipe had antibodies against influenza A(H1N1)pdm09; this percentage reached $30 \%$ of the population between 0 and 18 years and $6.1 \%$ among those over 19 years. The age variable was the only factor that evidenced significant differences in the prevalence of antibodies. There were no significant differences related to gender, vaccination history against seasonal inluenza, or comorbidity. $51 \%$ of people with positive serology showed IN-FLUENZA-LIKE SYMPTOMS. Conclusions: A relevant percentage of subclinical disease was detected in the first pandemic wave in Chile and the proportion of people with SARI and deaths was small. Data from epidemiological surveillance were useful to estimate the trend of TSI but not its magnitude.

Keywords: Influenza A(H1N1)pdm09; Influenza Seroprevalence

\section{INTRODUCTION}

Chile, along with other countries in the temperate zone of the southern hemisphere, was one of the first countries strongly affected by the influenza A(H1N1)pdm09 virus at the beginning of the pandemic wave. The first case was confirmed on May 17, 2009 and until December of the same year, 368,118 cases of influenza like illness(ILI) were notified in the whole country; 12,302 cases of specific PCR in real time were confirmed and 634,450 people from both the public and private health system were delivered for free antiviral treatments. During the same period, 1622 cases of severe acute respiratory infection (SARI) due to H1N1 (2009) and 150 deaths (deaths related to pandemic influenza) were confirmed. Among the cases of ILI, the highest rate corresponded to the $5-14$ year-old layer, followed by the $<5$ year-old layer; the $\geq 60$ year-old layer showed the lowest rate. The pandemic influenza activity peaked between the epidemiological weeks (EW) 26 and 28, and then it declined and remain- 
ed low from the week $30.99 \%$ of the influenza A viruses that circulating in Chile during 2009 corresponded to the influenza A H1N1(2009) [1] virus.

In this context and considering the need to know the natural history of the first wave of pandemic H1N1(2009) influenza in the Southern hemisphere, the Ministry of Health in Chile through its Department of Epidemiology and the Panamerican Health Organization and the Centers for Disease Control and Prevention in Atlanta carried out a seroprevalence study at the end of the first pandemic wave. The aim was to detect antibodies against influenza A (H1N1) 2009 in a selected community, in order to estimate the population attack rate and its variations, the consultation rates, hospitalization and mortality rates, while describing the control measures implemented.

The study was designed and funded jointly by the three entities involved (Epidemiology-MINSAL-Chile, PAHO, CDC in Atlanta), including the payment of extra human resources, their training, the installation of a laboratory for RT-PCR in San Felipe town and the purchase of the necessary laboratory supplies for IFI and PCR-RT testing. The sample design was commissioned to the Center for Microdata of the Economics Faculty of the University of Chile; the gathering of in-situ information and samples was carried out by the Pediatrics Division and the Department of Public Health of the Pontifical Catholic University of Chile. The laboratory analysis was carried out by the Sub-Department of Virology at the Public Health Institute of Chile.

\section{MATERIAL AND METHODS}

The design corresponds to a cross-sectional analytical study by administrating a serological survey to a random and representative sample of the population of the San Felipe commune to measure the infection prevalence with the Influenza A(H1N1)pdm09 virus at the end of the first pandemic wave (January 2010). In order to carry out the study, San Felipe commune which is located $94 \mathrm{~km}$ northern Santiago in Chile (32 $45^{\prime}$ South latitude $70^{\circ} 43^{\prime}$ West longitude) was chosen for having easy ways of access from Santiago, the capital city, and for having a small population and the $78 \%$ of them gets medical attention from the public health facilities in town. San Felipe has an area of $186 \mathrm{~km} 2$ and the population is of 75.412 inhabitants, $92 \%$ urban (estimate in 2009 by the $\mathrm{NIS}^{1}$ ).The health infrastructure includes a base 226-bed hospital, an Emergency Primary Health Care Service, two urban General Practices Centers and a rural Primary Care Center. The Commune does not have private hospitals, only outpatient facilities of the Chilean Safety Association and of the Institute of Work Safety.

\footnotetext{
${ }^{1}$ National Institute of Statistics.
}

Sample-Size Calculation. A stratified random sampling by age groups $(0-4$ years old, 5 - 18 years old and $19+$ years old) was carried out, using the consumption of antiviral in the commune as the estimate of prevalence (attack rate); that is, given that in Chile free antiviral treatment was delivered to all people who suffered from a TSI and that the main of the influenza viruses circulating in 2009 was the influenza A(H1N1)pdm09 virus, it is possible to assume that the number of treatments provided are a good approximation to the number of the people who got ill. For the $0-4$ years old and $19+$ years old strata, it was considered a $2 \%$ attack rate, a $1.5 \%$ absolute error and a $95 \%$ confidence level, while for the stratum 5 - 18 years old, it was considered a $6 \%$ attack rate, a $2 \%$ absolute error and a $95 \%$ confidence level. The initial calculation of the sample size was amplified by 2.0 (design effect), reaching a sample size of 2.350 subjects, to which it was added $30 \%$ on account of oversampling (3.055 subjects) (Table 1).

0 - 4 year-old and 5 - 18 year-old stratum were over-represented while the 19+ was underrepresented in the sample. By expanding the sample, its composition by age was equal to the population of the commune of San Felipe.

Multistage Design and Registration. To ensure representative population, subjects were selected based on multistage random sampling; blocks were the primary sample units, dwellings were the secondary and people the tertiary. 3.077 dwellings were registered which produced a list of addresses to visit and subjects to contact during the field work.

\subsection{The Instrument}

A 35 question questionnaire was designed with information about demographic aspects identification, birth date, marital status, welfare, educational level, employment), clinical aspects (morbid history, pregnancy) and epidemiological information (influenza-like symptoms between May and September 2009, medical consultation, test taking, hospitalization, antiviral therapy, 2009 seasonal antiinfluenza vaccination history, people ill at home).

\subsection{Ethical Aspects}

The study was approved by an ad-hoc ethics committee constituted to review all the studies related to the 2009 Pandemic Influenza and by the Ethics Committee of the Pontifical Catholic University of Chile; it counted with an informed consent that had to be signed by everyone over 18 years old and the parents (or legal tutors) of minors, as well as the consent of children and adolescents between 7 and 17 years old. 
Table 1. Population of the San Felipe commune, sample size and subjects surveyed with blood samples according to age strata.

\begin{tabular}{ccccccc}
\hline \multirow{2}{*}{ Age } & Population (a) & Sample & & \multicolumn{2}{c}{ Subjects surveyed } & \multicolumn{3}{c}{ Subjects with blood samples } \\
\cline { 4 - 7 } & & & $\mathrm{n}$ & $\%(\mathrm{~b})$ & $\mathrm{n}$ & \% (c) \\
\hline $0-4$ & 5.848 & 634 & 527 & 83.1 & 393 & 74.6 \\
$5-18$ & 17.567 & 1050 & 1.111 & 105.8 & 1.028 & 92.5 \\
$19+$ & 52.541 & 666 & 812 & 121.9 & 769 & 94.7 \\
Total & 75.956 & 2.350 & 2.450 & 104.3 & 2.190 & 89.4 \\
\hline
\end{tabular}

(a) Population estimate (Linear interpolation value, Dic. 2010), Deff: design effect $(2,0)$. (b) The denominator corresponds to the sample size of the corresponding stratum. (c) The denominator corresponds to the surveyed of the corresponding stratum.

\subsection{Funding}

The study was funded by the Ministry of Health, the Panamerican Health Organization and the Centers for Disease Control and Prevention (CDC), Atlanta, United States of America.

\subsection{Field Work and Sampling}

The field work was carried out in 8 weeks, from January to the first fortnight of March 2010. The samplings were taken by university-educated nurses through venous puncture in the crook of the elbow, collecting $10 \mathrm{ml}$ (adults) or $5 \mathrm{ml}$ (children under $30 \mathrm{~kg}$ ). The samples were labeled and transported in cold chain to the commune hospital. The questionnaires were administered once the samples were taken.

\subsection{Procedures and Laboratory Analysis}

In the laboratory of the San Camilo Hospital of San Felipe, the samples were centrifuged to remove blood serum which was stored at $-20^{\circ} \mathrm{C}$. Weekly, the samples were transferred to the Respiratory Viruses and Exanthematous Section of the Subdepartment of Clinical Virology of the Public Health Institute (PHI) where the study of the antibodies against the A(H1N1)pdm09 virus, by the technique of the hemagglutination inhibition (HI) according to standarized methodology [2].

The sera were previously treated with receptor destroying enzyme (RDE, vibrio cholerae Neuraminidase, Denka Seiken Corporation, Ltd., Tokio, Japón), incubated at $37^{\circ} \mathrm{C}$ to inactivate nonspecific inhibitors of hemagglutination. The samples were then incubated at $56^{\circ} \mathrm{C}$ for 30 minutes to inactivate the RDE.

As an antigen, a strain of the pandemic influenza $A$ (H1N1) virus was used, the A/Santiago/34116/09 (H1N1) 20009, isolated from a patient in embryonated chicken eggs at the PHI an confirmed by RT-PCR in real time, using the primers and the recommended protocol by the CDC [3].

The hemagglutination was carried out with turkey erythrocytes at a concentration of $0.5 \%$. Controls provided by the CDC were used: a control antigen strain 2009 A
(H1N1) (A/California/7/2009) and a reference antiserum for 2009 A (H1N1).

The assay was performed in duplicate for each of the samples from an initial dilution of 1:10 to a final dilution of $1: 1.280$.

The results were recorded as titers or geometric medians corresponding to the reciprocal of the highest positive dilution.

In the present study, the proportion of subjects with antibody titers $\geq 1: 40$ were considered positive and termed seroprevalence.

\subsection{Statistical Analysis}

The statistical analysis was carried out using the module "Complex Samples" of the SPSS software, version 15.0. Two types of expansion factors were calculated: one for the subjects who completed the questionnaire and one for the subjects who provided blood samples. Not all the subjects who answered the questionnaire provided blood samples (Table 1).

The overall and specific antibodies prevalence as well as the clinical attack rate ${ }^{2}$, were calculated according to the age strata $^{3}$. Those subjects who reported influenza like illness (fever above $38^{\circ} \mathrm{C}$ with coryza or cough) between May 1 and September 1, 2009 were considered clinical cases. The subjects were classified into four stages according to the associated antibodies and the symptomatic illness: symptomatic seropositive, asymptomatic seropositive, symptomatic seronegative and asymptomatic seronegative. Odds ratios were calculated according to age strata $(0-4,5$ - 18 y 19+ years old), sex, medical welfare (Fonasa, public sector/Isapre, private sector), 2009 seasonal anti influenza vaccine history and comorbidities $(0,1, \geq 2$ morbid history, as cancer, diabetes, asthma, heart diseases, COPD, hypertension, smoking, obesity, HIV/AIDS). A logistic regression model (ENTER modality) was used for the adjustment of odds ratios.

\footnotetext{
${ }^{2}$ Clinical attack rate $=\mathrm{n}^{\circ}$ of subjects with positive report of influenza like illness/total $n^{\circ}$ total of surveyed subjects ${ }^{*} 100$.

${ }^{3}$ Global and specific prevalence of antibodies $=n^{\circ}$ of subjects with positive blood serum/total $n^{\circ}$ of blood sample donors ${ }^{*} 100$.
} 
In the same way, the rates of use of antiviral drugs, consultations and hospitalizations were calculated [4] in order to describe the access of the population to health services.

Based on the anti influenza A H1N1-2009 antibodies prevalence and the influenza like symptoms prevalence found in San Felipe, the theoretical number of subjects with anti influenza A H1N1-2009 positive serum for the total Chilean population [4] was estimated.

\section{RESULTS}

3.077 subjects were registered, 2.919 visits were made completing 2.450 questionnaires. This figure exceeded in
$4.3 \%$ the estimated sample size (Table 1); 2.190 subjects (89\%) provided blood samples, being the $0-4$ year-old stratum the smaller group (74.6\%).

Table 2 shows the main demographic, clinical and epidemiological characteristics of the 2.450 subjects surveyed, according to age strata.

The population prevalence of antibodies against influenza 2009 A (H1N1) was 13.5\% (CI 95\%; 11.3 - 15.9), reaching about $30 \%$ in the $0-4$ and $5-18$ year-old strata, while in those $19+$ only reached $6.1 \%$. Age was the only variable that showed significant differences in the prevalence of antibodies (Table 3).

Although the antibodies prevalence was higher among

Table 2. Description of the 2.450 subjects surveyed, according to age stratum.

\begin{tabular}{|c|c|c|c|c|}
\hline \multirow[b]{2}{*}{ Age (years) } & \multicolumn{4}{|c|}{ Subjects surveyed (\%) } \\
\hline & $0-4(n=527)$ & $5-18(\mathrm{n}=1.111)$ & $19+(\mathrm{n}=812)$ & Total $(\mathrm{n}=2.450)$ \\
\hline \multicolumn{5}{|l|}{ Gender } \\
\hline Female & $270(51.2)$ & $573(51.6)$ & $486(59.9)$ & $1.329(54.2)$ \\
\hline Male & $256(48.6)$ & $537(48.3)$ & $326(40.1)$ & $1.119(45.7)$ \\
\hline \multicolumn{5}{|l|}{ Welfare $^{a}$} \\
\hline Fonasa & $464(88.0)$ & $949(85.4)$ & $651(80.2)$ & $2.064(84.2)$ \\
\hline Isapre & $30(5.7)$ & $70(6.3)$ & $50(6.2)$ & $150(6.1)$ \\
\hline \multicolumn{5}{|l|}{ Other } \\
\hline \multicolumn{5}{|c|}{ Home inhabitants ${ }^{\mathrm{b}}$} \\
\hline 4 or less & $238(45.2)$ & $654(58.9)$ & $594(73.2)$ & $1.486(60.7)$ \\
\hline 5 or more & $270(51.2)$ & $445(40.1)$ & $173(21.3)$ & $888(36.2)$ \\
\hline \multicolumn{5}{|l|}{ Comorbility $^{\mathrm{c}}$} \\
\hline 0 & $461(87.5)$ & $920(82.8)$ & $384(47.3)$ & $1.765(72.0)$ \\
\hline 1 & $39(7.4)$ & $157(14.1)$ & $274(33.7)$ & $470(19.2)$ \\
\hline 2 or more & - & $11(1.0)$ & $148(18.2)$ & $159(6.5)$ \\
\hline \multicolumn{5}{|l|}{ Vaccine $2009^{d}$} \\
\hline Yes & $211(40.0)$ & $153(13.8)$ & $289(35.6)$ & $653(26.7)$ \\
\hline No & $311(59.0)$ & $946(85.1)$ & $521(64.2)$ & $1.778(72.6)$ \\
\hline
\end{tabular}

(a) Other: FF. AA, another system, none, does not known. (b) $\mathrm{N}^{\circ}$ Home inhabitant. (c) Comorbility: the presence of the following pathologies: cancer, diabetes, asthma, cardiopathology, EPOC, arterial hypertension, smoking, obesity, HIV/AIDS. (d) 2009 seasonal anti influenza vaccination history.

Table 3. Prevalence of the antibodies against the influenza A H1N1-2009 virus in the commnune San Felipe, according age stratum.

\begin{tabular}{ccccccc}
\hline & \multicolumn{2}{c}{ Blood Samples } & & Prevalence \% (IC 95\%) (b) & \multicolumn{2}{c}{ Odds Ratio (IC 95\%) } \\
\cline { 1 - 2 } Age & Analized & Positive & & & Gross & Adjusted (c) \\
\hline $0-4$ & 393 & 127 & $29.8(22.3-38.6)$ & $6.59(3.78-11.47)$ & $6.13(3.12-12.06)$ \\
$5-18$ & 1.028 & 306 & $30.2(25.0-35.9)$ & $6.71(4.20-10.73)$ & $6.70(3.79-11.83)$ \\
$19+$ & $768(\mathrm{a})$ & 47 & $6.1(4.2-8.7)$ & 1.00 & 1.00 \\
Total & $2.189(\mathrm{a})$ & 480 & $13.5(11.3-15.9)$ & & \\
\hline
\end{tabular}

(a) A subject gave an insufficient blood sample to give a result. (b) Prevalence calculated on the expanded sample. (c) Adjustment through the model of the logistic regression (ENTER modality) that incorporated the age, gender, number of home inhabitants, health welfare, 2009 anti influenza vaccination history and comorbility variables. 
women than men, among homes of more than 5 people, among affiliated to FONASA $^{4}$ (as compared to those affiliated to ISAPRE ${ }^{5}$ and among non vaccinated people against seasonal influence, these differences did not reach statistical signification (Table 4).

The prevalence among subjects that had influenzalike ${ }^{6}$ symptoms between May-September 2009 was $32.2 \%$; nonetheless, among people with positive antibodies, the influenza-like history nearly reached $51.5 \%$, while it reached $30.3 \%$ among the people without antibodies (Table 5).

There was no significant association between history of vaccination against seasonal influenza and the presence of influenza-like symptoms; $33.6 \%$ of the people with vaccination history presented influenza-like symptoms versus the $31.5 \%$ of people without vaccination history. Although, in all ages the proportion of people with history of vaccination was bigger among those who had influence-like symptoms as compared to those who did not show any symptoms, the differences did not reach

Table 4. Odds ratio gross and adjusted of anti influenza A H1N1-2009 positive serology for different variables (expanded sample).

\begin{tabular}{|c|c|c|c|}
\hline \multirow[b]{2}{*}{ Variable } & \multirow[b]{2}{*}{$\begin{array}{c}\text { Positive } \\
\text { Serology } \%\end{array}$} & \multicolumn{2}{|c|}{ Odds Ratio (IC95\%) } \\
\hline & & Gross & Adjusted $^{\mathrm{a}}$ \\
\hline \multicolumn{4}{|l|}{ Gender } \\
\hline Female & 13.9 & $1.09(0.74-1.61)$ & $1.29(0.86-1.92)$ \\
\hline Male & 12.9 & 1.00 & 1 \\
\hline \multicolumn{4}{|l|}{$\begin{array}{l}\mathrm{N}^{\circ} \text { of home } \\
\text { inhabitants }\end{array}$} \\
\hline 5 or more & 19.7 & $1.98(1.31-2.99)$ & $1.25(0.81-1.95)$ \\
\hline 4 or less & 11.1 & 1 & 1 \\
\hline \multicolumn{4}{|l|}{ Welfare } \\
\hline Fonasa & 14.6 & $1.50(0.67-3.37)$ & $1.19(0.59-2.41)$ \\
\hline Isapre & 10.2 & 1 & 1 \\
\hline \multicolumn{4}{|l|}{ Vaccination 2009} \\
\hline Neg. & 14.5 & $1.45(0.90-2.32)$ & $1.19(0.70-2.03)$ \\
\hline Pos. & 10.5 & 1 & 1 \\
\hline \multicolumn{4}{|l|}{ Comorbility $^{\mathrm{b}}$} \\
\hline One & 9.8 & $0.54(0.31-0.93)$ & $1.25(0.70-2.23)$ \\
\hline Two or more & 6.8 & $0.37(0.16-0.82)$ & $0.98(0.38-2.51)$ \\
\hline None & 16.7 & 1 & 1 \\
\hline
\end{tabular}

(a) Adjustment variables: age, gender, people in home, welfare, 2009 seasonal anti influenza vaccination and morbility history. (b) Comorbility: the presence of the following pathologies: cancer, diabetes, asthma, cardiopathology, EPOC, arterial hypertension, smoking, obesity, HIV/AIDS.

${ }^{4}$ Public health system.

${ }^{5}$ Private health system.

${ }^{6}$ Those subjects who answered positive the question: Did you have fever with coryza or cough between May 1 and September 2009, were considered as symptomatic. statistical significance.

$47 \%$ of subjects who reported influenza-like symptoms consulted for that cause. The proportion was higher among those with influenza positive serology, reaching $73 \%$ (Table 6).

Among these, children under 5 years old were those who showed the highest consultation rate $(95 \%)$. However, the 19+ stratum showed a difference in the consul0 tation rate between the total sample and the seropositive subjects.

Regarding the use of antiviral, $2.7 \%$ (95\% CI; 1.9 - 3.9) of subjects who answered the survey received antiviral treatment, increasing to $11.5 \%(95 \% \mathrm{CI} ; 6.9-18.4)$ among the seropositive subjects. In the first group (total subjects surveyed), the percentage decreased with age whereas among seropositive increased with age, reaching $15 \%$ among the $19+$ year-old stratum (Table 6).

Whereas 8 sample subjects were hospitalized, only one of them had anti-Influenza $\mathrm{A}(\mathrm{H} 1 \mathrm{~N} 1)$ pdm09 virus titers over 40 .

\section{DISCUSSION AND CONCLUSIONS}

This is a population-based study representative of a Chilean commune (San Felipe).

The attack rate of the first pandemic wave was $13.5 \%$ in the same commune, with the highest rates among those under 18 years old, confirming the relevance of this group in the transmission of influenza in the community. Whereas the prevalence of antibodies was higher among non vaccinated people against seasonal influenza, it is not possible to confirm the relationship between those variables. Seropositive people had more influenza-like symptoms, consulted more and received more antiviral than the average population.

The results of this study showed that $73 \%$ of seropositive people consulted due to influenza-like symptoms and only $11 \%$ of them say they received antiviral treatment. This fact is outstanding considering the protocol instructed by the Ministry of Health who stated that all the people who consulted because of influenza-like symptoms would receive free antiviral treatment.

Considering in San Felipe age ETI rates and antiviral delivery were very similar to the national average, it is possible to assume that those results can be generalized to the rest of the country (Table 7).

According to this study, the pyramid of disease severity in San Felipe had a base of $13.5 \%$ people infected serologically (representing 10.181 people), $51.5 \%$ of the people with positive serology had symptoms caused by pandemic $\mathrm{A}(\mathrm{H} 1 \mathrm{~N} 1)$ influenza (which represents $7 \%$ of the total population); $73 \%$ of them consulted because of the symptoms (representing $5.1 \%$ of the commune population). Finally, 8 people from the sample were hospitalized for ILI, and only 1 had positive serology; there were 
Table 5. Influenza like symptoms among seropositive and seronegative subjects.

\begin{tabular}{cccccc}
\hline Age & $\begin{array}{c}\text { With Symptoms \% } \\
\text { (IC; 95\%) (a) }\end{array}$ & \multicolumn{2}{c}{ Seropositives (\%) (a) } & \multicolumn{2}{c}{ Seronegatives (\%) (a) } \\
\hline & & With Symptoms & Without Symptoms & With Symptoms & Without Symptoms \\
$0-4$ & $58.2(50.3-65.7)$ & 59.4 & 40.6 & 56.5 & 43.5 \\
$5-18$ & $46.8(41.1-52.5)$ & 55.4 & 44.6 & 43.3 & 56.7 \\
$19+$ & $24.3(19.8-29.6)$ & 40.7 & 59.3 & 24.8 & 75.2 \\
Total & $32.2(28.5-36-1)$ & 51.5 & 48.5 & 30.3 & 69.7 \\
\hline
\end{tabular}

(a) Prevalence estimated over the expanded sample.

Table 6. $\%$ of consultations because of IT and use of antivirals among the total population surveyed and population with positive serology.

\begin{tabular}{ccccc}
\hline \multirow{2}{*}{ Age (years) } & \multicolumn{2}{c}{$\%$ consultations because of IT (a) } & \multicolumn{2}{c}{$\%$ antiviral use (a) } \\
\cline { 2 - 5 } & Subjects Surveyed & Seropositive Subjects & Subjects Surveyed & Seropositive Subjects \\
\hline $0-4$ & $88,8(80.0-94.1)$ & $95.8(89.6-98.4)$ & $4.7(2.0-10.3)$ & $5.8(2.8-11.9)$ \\
$5-18$ & $57.2(50.7-63.5)$ & $66.1(53.2-76.9)$ & $5.2(3.2-8.4)$ & $11(5.4-21.2)$ \\
$19+$ & $36.6(29.1-44.8)$ & $73.9(56.2-86.2)$ & $1.7(0.9-3.1)$ & $15(6.3-31.5)$ \\
Total & $46.9(41.5-52.4)$ & $73.1(63.9-80.6)$ & $2.7(1.9-3.9)$ & $11.5(6.9-18.4)$ \\
\hline
\end{tabular}

(a) Prevalence estimated over the expanded sample.

Table 7. Estimation at national level on the theoretical number of subjects with anti influenza A H1N1-2009 serology, according to age stratum.

\begin{tabular}{|c|c|c|c|}
\hline \multirow{2}{*}{ Age } & Population $^{\mathrm{a}}$ & Seroprevalence ${ }^{\mathrm{b}}$ & Theoretical Cases \\
\hline & $\mathrm{n}$ & $\%$ & $\mathrm{n}$ \\
\hline $0-4$ & 1.248 .325 & $\begin{array}{c}29.8 \\
(22.3-38.6)\end{array}$ & $\begin{array}{c}372.001 \\
(278.377-481.854)\end{array}$ \\
\hline $5-18$ & 4.054 .748 & $\begin{array}{c}30.2 \\
(25.0-35.9)\end{array}$ & $\begin{array}{c}1.224 .534 \\
(1.013 .687-1.455 .655)\end{array}$ \\
\hline $19+$ & 11.791 .197 & $\begin{array}{c}6.1 \\
(4.2-8.7)\end{array}$ & $\begin{array}{c}719.263 \\
(495.231-1.025 .835)\end{array}$ \\
\hline Total & 17.094 .270 & - & $\begin{array}{c}2.315 .798 \\
(1.787 .295-2.963 .344)\end{array}$ \\
\hline
\end{tabular}

(a) Estimated Population (Chile 2010). (b) Prevalence calculated in the present study for the commune of San Felipe, Value between brackets: IC 95\%.

no deceased people in the sample.

World studies on antibody prevalence against 2009 A (H1N1) influenza show variable results. So, it is possible to find a $6 \%$ in Pune, India [5], $15.7 \%$ among pregnant women in Manitoba, Canada [6], 18.2\% among under 15 years old in England [7], 18.8\% among non vaccinated people against H1N1 in China [8], 29.5\% in New Zealand [9], 28.4\% in Australia [10], 29.7\% in Taiwan [11]. The study carried out in the San Felipe commune shows an antibody prevalence relatively low as compared to other studies that have measured post pandemic prevalence of antibodies against influenza A(H1N1)pdm09 virus that could be partly explained by differences in the methodology to obtain the samples. In San Felipe it had a representative sample of the population base.

On the other hand, studies suggest that there would be a proportion of the population, especially older adults, with pre-existing immunity to the pandemic H1N1 virus (England), due to prior exposure to antigenically related viruses related to the influenza $\mathrm{H} 1 \mathrm{~N} 1$ virus that circu- 
lated the first half of the twentieth century. This pre-existing immunity varies from $0.9 \%$ in Pune, India [5], $1.8 \%$ among under 5 years old to $31 \%$ among 80 yearold adults (England) [7]; 12.8\% in New South Wales, Australia [10], 7.1\% in Canada [11], $11.9 \%$ in New Zealand [9], 45\% among $>80$ year-old subjects [12], 24\% among $>65$ year-old subjects [13].

The latter estimate was not obtained in San Felipe, so obtained results could overestimate the real impact that the first pandemic wave had in that commune. On the other hand, it gives important information in terms of the structure of the pandemic severity, from subclinical infection and asymptomatic until the SARI. Furthermore, it gives evidence about the necessary considerations when interpreting the results of the epidemiological surveillance of influenza.

\section{REFERENCES}

[1] Ministerio de Salud de Chile. Influenza pandémica (h1n1) (2009) Reporte Situación 2009. Ministerio de Salud de Chile, Enero de 2010.

http://www.pandemia.cl/templates/pandemia/documentos Informe 13 enero.pdf

[2] World Health Organization (2011) WHO Global Influenza Surveillance Network. Manual for the laboratory diagnosis and virological surveillance of influenza. http://www.who.int/csr/disease/influenza/manual_diagno sis surveillance influenza/en/index.html

[3] (2009) WHO information for laboratory diagnosis of pandemic (H1N1) 2009 virus in humans.

http://www.who.int/csr/resources/publications/swineflu/r ealtimeptpcr/en/index.html

[4] Ministerio de Salud de Chile (2010) Guía Clínica para el Diagnóstico y Manejo Clínico de Casos de Influenza Pandémica (H1N1) 2009, Versión: 4.0. Ministerio de Salud de Chile, Abril 2010.

http://www.pandemia.cl/templates/pandemia/documentos /Guia_Clinica_Caso2010_v_280410.pdf

[5] Tandale, B., Pawar, S., Gurav, Y., Chadha, M., Koratkar, S., Shelke, V., et al. (2010) Seroepidemiology of pandemic influenza A (H1N1) 2009 virus infections in Pune, India. BMC Infectious Diseases, 10, 255. http://www.biomedcentral.com/1471-2334/10/255 http://dx.doi.org/10.1186/1471-2334-10-255

[6] Mahmud, S., Becker, M., Keynan, Y., Elliott, L., Thompson, L., Fowke, K., et al. (2010) Estimated cumulative incidence of pandemic (H1N1) influenza among pregnant women during the first wave of the 2009 pandemic. CMAJ, 182, 14. http://dx.doi.org/10.1503/cmaj.100488

[7] Miller, E., Hoschler, K., Hardelid, P., Stanford, E., Andrews, N. and Zambon, M. (2010) Incidence of 2009 pandemic influenza A H1N1 infection in England: A crosssectional serological study. Lancet, 375, 1100-1108. http://dx.doi.org/10.1016/S0140-6736(09)62126-7

[8] Tian, L.L., Shi, W.-X., Ying, D., Pang, X.-H., Peng, Y., Fang, H., Shu, J.C., Xin, Z., Zhang, D.-T. and Wang, Q.-Y. (2011) Serologic survey of pandemic influenza A (H1N1 2009) in Beijing, China. Preventive Medicine, 52, 71-74.

http://www.sciencedirect.com/science/article/pii/S009174 3510004263 http://dx.doi.org/10.1016/j.ypmed.2010.10.006

[9] Bandaranayake, D., Huang, Q.S., Bissielo, A., Wood, T., Mackereth, G., et al. (2010) Risk factors and immunity in a nationally representative population following the 2009 influenza $\mathrm{A}(\mathrm{H} 1 \mathrm{~N} 1)$ pandemic. PLoS ONE, 5, e13211. http://dx.doi.org/10.1371/journal.pone.0013211

[10] Gilbert, G.L., Cretikos, M.A., Hueston, L., Doukas, G., O'Toole, B., et al. (2010) Influenza A (H1N1) 2009 antibodies in residents of New South Wales, Australia, after the first pandemic wave in the 2009 Southern Hemisphere Winter. PLOS ONE, 5, e12562.

[11] Chao, D.-Y., Cheng, K.-F., Li, T.-C., Wu, T.-N., Chen, C.-Y., et al. (2011) Serological evidence of subclinical transmission of the 2009 pandemic H1N1 influenza virus outside of Mexico. PLOS ONE, 6, e14555. http://dx.doi.org/10.1371/journal.pone.0014555

[12] Ikonen, N., Strengell, M., Kinnunen, L., et al. (2009) High frequency of cross-reacting antibodies against 2009 pandemic influenza $\mathrm{A}(\mathrm{H} 1 \mathrm{~N} 1)$ virus among the elderly in Finland. Euro Surveill, 15, 19478.

[13] Rizzo, C., Rota, M.C., Bella, A., et al. (2010) Cross-reactive antibody responses to the $2009 \mathrm{~A} /(\mathrm{H} 1 \mathrm{~N} 1) \mathrm{v}$ influenza virus in the Italian population in the pre-pandemic period. Vaccine, 28, 3558-3562. http://dx.doi.org/10.1016/j.vaccine.2010.03.006 